\title{
Evaluation of serum gamma glutamyl transferase activity among type-2 diabetic patients in Erbil
}

\begin{tabular}{l}
\hline \multicolumn{1}{c}{ Syan Asad Qadir $^{1} \quad$ Sardar Nouri Ahmed ${ }^{2 *}$} \\
\hline Abstract \\
Background and objective: Gamma-glutamyl transferase is an enzyme that catalyzes the \\
transfer of a glutamyl residue the acceptor through the glutamates gamma carboxylic acid \\
to an amino acid. This study aimed to evaluate the serum gamma glutamyl transferase \\
activity in type 2 diabetic patients and find out other confounding factors like age and \\
gender effects.
\end{tabular}

Methods: A cross-sectional study was carried out from January to June 2016 in collaboration between the Clinical Biochemistry Department at the College of Medicine, Hawler Medical University and the Chemistry Department at the Faculty of Science and Health of Koya University. The study included 50 type 2 diabetic patients (group 1), and 50 healthy individuals (group 2).

Results: The mean value of serum gamma glutamyl transferase activity was significantly higher in type 2 diabetic patients (group 1) than that of healthy individuals (group 2) $(P<0.001)$. The mean value of serum gamma glutamyl transferase activity in men diabetic patients was non significantly lower than women diabetic patients. The mean value of serum gamma glutamyl transferase activity in diabetic patients whose age was $\geq 50$ years was non significantly higher than diabetic patients whose age was $<50$ years.

Conclusion: Based on the findings of the present study, it can be concluded that high serum gamma glutamyl transferase activity is an independent factor and has considerable potential in diagnosing and monitoring for type 2 diabetic patients.

Keywords: Serum gamma glutamyl transferase; Age; Gender; HbA1C; Type 2 diabetes mellitus.

\section{Introduction}

Diabetes mellitus is characterized by chronic hyperglycemia with disturbance of carbohydrate, protein, and fat metabolism resulting from defects in insulin secretion, insulin action, or both. ${ }^{1}$ Type 2 diabetes is a type of diabetes that accounts for 90-95 of those with diabetes previously called non-insulin dependent diabetes mellitus (NIDDM), or adult-onset diabetes, may range from predominantly insulin resistance with relative deficiency. ${ }^{2}$ Gamma -glutamyl transferase (GGT) (E.C.2.3.2.2) is found in the liver, kidneys, biliary system, pancreas, and intestine briefly, catalyzes the transfer of a glutamyl residue an acceptor through the glutamates gamma carboxylic acid of an amino acid. $^{3}$ The most abundant natural substrate is glutathione. Glutathione is extracellular and cannot penetrate through the cell membrane. Glutathione can be broken down into three amino acids (glycine, cysteine, and glutamate). GGT activity, normally found in the plasma membrane of virtually all cells except erythrocytes, catalyzes the first step in the degradation of extracellular glutathione (GSH), allowing the precursor amino acids to be assimilated and reutilized for intracellular GSH synthesis. ${ }^{4}$ Thus, GGT activity favors the cellular supply of $\mathrm{GSH}$, the most important non-protein antioxidant of the cell. However, there is also clear evidence

${ }^{1}$ Department of Chemistry, Faculty of Science and Health, Koya University, Erbil, I raq.

2 Department of Clinical Biochemistry, College of Medicine, Hawler Medical University, Erbil, I raq.

* Correspondence: Sardarna2007@yahoo.com 
that the degradation of GSH can play a pro -oxidant role. ${ }^{5}$ Gama glutamyl transferase is therefore thought to have a role in oxidative mechanisms and is regarded as an early and sensitive marker of oxidative stress. ${ }^{6}$ In many prospective studies, strong relationships between GGT and alanine transaminase (ALT) concentrations and incident diabetes have also been observed in non-drinkers, in individuals with normal levels of liver enzymes, independently of classical cardiovascular risk factors. ${ }^{7}$ However, a strong interaction between body mass index (BMI), and GGT has been described in diabetes. ${ }^{8}$ Several resembles have reported that increased GGT is independently associated with increased risk of type-2 diabetes in Asian and Caucasian. ${ }^{9}$ Although serum GGT activity has been commonly used as a marker for excessive alcohol consumption or liver disease, serum GGT has shown a strong graded relationship with incident diabetes, suggesting $a$ role in the pathogenesis of diabetes. ${ }^{10}$ This study aimed to investigate serum GGT activity in type-2 diabetes in order to evaluate its role in the diagnosis and complication of type- 2 diabetes.

\section{Methods \\ Subjects}

The cross-sectional study with a comparison group was conducted over a period of six months, from January to July 2016 . The subjects included 50 type-2 diabetic patients (30 men and 20 women) as group 1 with a mean age of $53.46 \pm 9.55$, and 50 healthy volunteers (30 men and 20 women) as group 2 with a mean age of $55.15 \pm 6.5$. All the cases in both groups (1 and 2) were non smokers and non alcohol drinkers.

\section{Serum sampling}

Four to six milliliters of venous blood was withdrawn from each individual using a disposable syringe. The samples were obtained from Layla Qasim specialized center for diabetic patients in Erbil. The samples after half hour were centrifuged for
10 minutes at $3000 \mathrm{rpm}$, and the obtained serum (S) was analyzed directly.

\section{Methods}

\section{Estimation of serum gamma glutamyl transferase (GGT) \\ Principle of method}

This GGT activity procedure is by Szasz, Rosalki and Tarlow procedure. ${ }^{11}$

L-G-Glutamyl-P-Nitroanalide + Glycyl glycine

\section{L-G-Glutamyl-Glycyl glycine + P-Nitroaniline}

The rate of formation of $\mathrm{P}$-nitroaniline is directly proportional to the GGT activity in the sample, and is measured at $450 \mathrm{~nm}$.

Expected value:

Men (IU/L): $\quad 2-30$

Women (IU/L): 1-24

\section{Statistical analysis}

The statistical evaluation of the results [mean, standard deviation (SD) and standard error of the mean (SE)] was calculated using the scientific calculator (prop, 4h, 105). The different variables were compared to each other; simple correlations were tested with the t-test for two independent samples. A $P$ value of $<0.05$ was regarded as statistically significant. $^{12}$

\section{Results}

The activity of serum gamma glutamyl transferase (GGT)

Table 1 provides the mean serum GGT activity in type 2 diabetic patients and normal groups. The results obtained indicates that the mean $( \pm S D)$ serum GGT activity was $44.98 \pm 22.88 \mathrm{IU} / \mathrm{L}$ in type 2 diabetic patient group. This value was significantly $(P<0.001)$ higher than that obtained in the control group (14.24 $\pm 5.13 \mathrm{IU} / \mathrm{L})$.

Serum glucose concentration (mg/dl) and $\mathrm{HbA} 1 \mathrm{c} \%$

Table 2 shows the mean serum glucose in type 2 diabetic patients and control groups. The results obtained indicates that the mean $( \pm S D)$ serum glucose was 
$272.38 \pm 72.88 \mathrm{IU} / \mathrm{L}$ in type 2 diabetic significantly $(P<0.001)$ than that obtained patient group. This value was significantly $(P<0.001)$ higher than that obtained in the control group $(108.44 \pm 25.13 \mathrm{IU} / \mathrm{L})$. The same table provides the mean serum $\mathrm{HbA1C}$ in type 2 diabetic patients and normal groups. The mean $( \pm S D)$ serum $\mathrm{HbA} 1 \mathrm{C}$ was $9.83 \pm 2.8 \%$ in type 2 diabetes mellitus (Group 1). This value was higher in the control group $(5.67 \pm 1.2 \%)$. The simple correlation ( $r$-value) between serum glucose and $\mathrm{HbA} 1 \mathrm{C}$ in diabetic patients was $0.73(P<0.001)$. The simple correlation (r-value) between serum glucose and $\mathrm{HbA} 1 \mathrm{C}$ in control group was $0.7368(P<0.001)$.

Table 1: The mean \pm S.D of serum gamma-glutamyl transferase activity in normal and type 2 diabetic patient groups.

\begin{tabular}{llccc}
\hline Groups & Gender & N & $\begin{array}{c}\text { Serum GGT(IU/L) } \\
\text { (Mean } \pm \text { S.D) }\end{array}$ & P value \\
\hline $\begin{array}{llcc}\text { Type 2 Diabetes mellitus } \\
\text { (Group 1) }\end{array}$ & Men & 30 & $53.07 \pm 29.1$ & \\
& Women & 20 & $60.9 \pm 47.26$ & $0.471^{*}$ \\
& Both & 50 & $44.98 \pm 22.88$ & \\
Control & Men & 30 & $15.82 \pm 5.5$ & \\
(Group 2) & Women & 20 & $14.44 \pm 4.53$ & $0.84^{* *}$ \\
& Both & 50 & $14.24 \pm 5.13$ & $<0.001^{* * *}$ \\
\hline
\end{tabular}

*Between men and women in G1

${ }^{* *}$ Between men and women in G2

*** between $\mathrm{G} 1$ and $\mathrm{G} 2$

Table 2: The mean \pm S.D of serum glucose and $\mathrm{HbA} 1 \mathrm{c} \%$ in normal and type 2 diabetic patient groups.

\begin{tabular}{|c|c|c|c|c|c|c|}
\hline Groups & Gender & $\mathbf{N}$ & 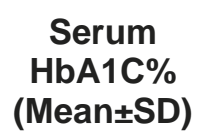 & $P$ value & $\begin{array}{c}\text { Serum glucose } \\
\text { (mg/dl) } \\
\text { (Mean } \pm S D)\end{array}$ & $P$ value \\
\hline \multirow{3}{*}{$\begin{array}{l}\text { Type } 2 \text { Diabetic } \\
\text { patients } \\
\text { (Group 1) }\end{array}$} & Men & 30 & $9.52 \pm 2.9$ & & $266.67 \pm 72.1$ & \\
\hline & Women & 20 & $9.13 \pm 2.6$ & $0.62^{*}$ & $262.69 \pm 65.96$ & $0.84^{*}$ \\
\hline & Both & 50 & $9.83 \pm 2.8$ & & $272.38 \pm 72.88$ & \\
\hline \multirow{3}{*}{$\begin{array}{l}\text { Normal } \\
\text { (Group 2) }\end{array}$} & Men & 30 & $5.62 \pm 1.24$ & & $105.82 \pm 25.5$ & \\
\hline & Women & 20 & $5.54 \pm 1.1$ & $0.81^{* *}$ & $104.44 \pm 4.53$ & $0.85^{* *}$ \\
\hline & Both & 50 & $5.67 \pm 1.2$ & $<0.001^{* * *}$ & $108.54 \pm 25.13$ & $<0.001^{* * *}$ \\
\hline $\begin{array}{l}{ }^{*} \text { Between men ar } \\
{ }^{* *} \text { Between men a } \\
{ }^{* * *} \text { between } \mathrm{G} 1 \text { ar }\end{array}$ & $\begin{array}{l}\text { women ir } \\
\text { d women } \\
\text { G2 }\end{array}$ & $\begin{array}{l}\mathrm{G} 1 \\
\mathrm{G} 2\end{array}$ & & & & \\
\hline
\end{tabular}


Table 3 shows the mean $\pm S . D$ of serum GGT level activity according to the age of diabetic patients (type 2) $(>50$ years, and $\leq 50$ years). The serum GGT of those aged $\geq 50$ years was non significantly $(P=0.56)$ higher than those aged less than 50 years.

\section{Discussion}

In this study, the mean activities of serum GGT was $14.24 \pm 5.13 \mathrm{IU} / \mathrm{L}$ in healthy individuals and $44.98 \pm 22.88 \mathrm{IU} / \mathrm{L}$ in type 2 diabetic patients. The mean activities of serum GGT in type 2 diabetic patients were significantly higher than that of healthy individuals $(P<0.001)$. The mean activities of serum GGT in type 2 diabetic patients are three times higher than that of normal individuals. Our results were in agreement with those obtained by another study. ${ }^{13}$ In the same table indicated that in type 2 diabetic patients, the mean activity of serum GGT in women was non significantly higher than that of men. The same results obtained by Ukayama $2011^{14}$ suggest by blood test results for GGT, which the normal range for men was 15-85 IU/L, whereas it was 5-55 IU/L for women. Elevated GGT could reflect subclinical inflammation, which would represent the underlying mechanism. In addition, certain mechanisms related to oxidative stress might play a role because cellular GGT has a central role in glutathione homeostasis by initiating the breakdown of extracellular glutathione, a critical antioxidant defense for the cell. Increases in serum GGT activity may be the response to oxidative stress, making increased transport of glutathione into cells, supporting a role of serum GGT in the inflammation and oxidative stress. ${ }^{15}$ Results of the current study shows that there was a significant difference in $\mathrm{HbA} 1 \mathrm{C} \%$ and serum glucose means of diabetic patients when compared to the normal non-diabetic group. This result is supported by Manjunatha et al. $2011 .^{16}$ In the current study, the HbA1C level of diabetic patients was found to be above $7 \%$. Also, the guidelines of American Diabetes Association which demonstrate that a $\mathrm{Hb} \mathrm{A} 1 \mathrm{C}$ of $6.5 \%$ or higher indicates a diagnosis of diabetes. ${ }^{17}$ In this study, we compared the mean \pm S.D of serum GGT level activity according to the age of diabetic patients (type 2) (> 50 years, and $\leq 50$ years) and the mean level of serum GGT was $45.88 \pm 16.34$ and $50.138 \pm 32.039$, respectively. Serum GGT of diabetic patients (type 2), ages equal or more than 50 years non significantly higher than that of diabetic patients (type 2) less than 50 years. The same results obtained by another study that a weak association between serum GGT and vascular diseases among older subjects. ${ }^{18}$ It is well known that hepatic metabolizing capacity of xenobiotics decreases with age, a phenomenon that reduces the ability to clear xenobiotics. At older compared to younger ages, the production of glutathione conjugates may be lower for a fixed level of exposure to xenobiotics. ${ }^{18,19}$ Increasing GGT activity was obtained by two other studies ${ }^{20,21}$ that found that there were an early diagnosis and impaired glucose tolerance (IGT), metabolic syndrome (MS), and nondiabetic first-degree relatives (FDR) of type 2 DM from the normal condition. Because this

Table 3: The mean \pm SD of serum gamma-glutamyl transferase activity according to the age of diabetic patients (type 2).

\begin{tabular}{lccc}
\hline Diabetic patients (No.) & N & serumGGT (Mean \pm SD) & $P$ value \\
\hline Less than 50 years & 25 & $45.88 \pm 16.34$ & \\
Equal or more than 50 years & 25 & $50.138 \pm 32.039$ & 0.56 \\
\hline
\end{tabular}


diagnostic test is a low-cost, highly sensitive, accurate, and frequently used laboratory test, its measurement is recommended as a useful marker of each of the IGT, MS, and FDR. Our study is in total agreement with other studies on patients with type 2 diabetes after a three year follow-up period had shown that raised GGT was correlated with the central obesity, increased FPG, TGs, and blood pressure in both sexes. ${ }^{22,23}$ In another study and when results of GGT, FPG, and TGs were compared. ${ }^{24}$ The concentrations of FPG and TGs markedly increased among the higher GGT categories. Similarly, the frequency of FPG and hypertriglyceridemia increased with the level of GGT.

\section{Conclusion}

The mean serum activity of GGT in type 2 diabetic patients was significantly higher than that of healthy individuals. So the measurement of serum activity of GGT may be used as a secondary biomarker in the diagnosis of diabetic patients. Serum GGT activity in women was non significantly higher than that of men in both groups, and GGT activity was increased according to the age in both groups. Based on current and experimental studies, we suggest that elevated serum GGT within its normal laboratory range might be an early and sensitive marker for oxidative stress. Serum GGT might be useful in studying oxidative stress-related issues in both and clinical settings.

\section{Competing interests}

The authors declare that they have no competing interests.

\section{References}

1. Zimmet $P$, Williams J, Courten M. Diagnosis and classification of diabetes mellitus in: John A., Wass and Stephen M. Shalet (eds). Oxford textbook of endocrinology and diabetes. New York: Heln Liepman; 2002. P. 1635.

2. Kaku K. Pathophysiology of type 2-diabetes mellitus and its treatment policy. JMAJ 2010; 53(1):41-6.
3. Dufour D, Lott J, Nolte F, Gretch D, Koff R, Seef L. Diagnosis and monitoring of hepatic injury performance characteristics of laboratory tests. Clin Chem 2000; 46(12):2027-49.

4. Whitfield JB. Gamma glutamyl transferase. Crit Rev Clin Lab Sci 2001; 38:263-355.

5. Emdin M, Pompella A, Paolicchi A. Gamma glutamyl transferase, atherosclerosis, and cardiovascular disease: triggering oxidative stress within the people. Circulation 2005; 112:2078-80.

6. Sharma R, Sharma S, Kaushik G. Gamma glutamyl transferase- a novel marker of endothelial dysfunction? JIACM 2010; 11(1):26-30.

7. Hanley AJ, Williams K, Festa A, Wagenknecht LE, Dagosteno RB, Kempf J, et al. Elevations in markers of liver injury and risk of type-2 diabetes; the insulin resistance atherosclerosis study. Diabetes 2004; 53(10):2623-32.

8. Nakanishi N, Nishana K, Li W, Sato M, Suzuki K, Tatara K. Serum gamma glutamyl transferase and development of impaired fasting glucose of type-2 diabetes in middle-aged Japanese men. $\mathrm{J}$ Intern Med 2033; 254(3):287-95.

9. Wannamethee SG, Lennon L, Shaper AG, Whincup $\mathrm{PH}$. Hepatic enzymes, the metabolic syndrome, and the risk of type-2 diabetes in older men. Diabetes Care 2005; 28(12):2913-8.

10. Lee DH, Jacohs DR, Gross M. Gamma glutamyl transferase is a predictor of incident diabetes and hypertension: the CARDIA study. Clin Chem 2003; 49(8):1358-66.

11. Talabani NS. Serum gammaglutamyltransferase activity: Inhibitory study in patient of hepatitis. IOSR-JAC 2013; 4(1):44-7.

12. Daniel WW, Chad L. Cross. Biostatistics: A foundation for analysis in the health science. $10^{\text {th }}$ ed. USA: John Wiley and Sons; 2013.

13. Baros AM, Wright TM, Latham PK, Miller PM, Anton RF. Alcohol consumption, \%CDT, GGT and blood pressure change during alcohol treatment. 2008. Alcohol and Alcoholism 2007; 43(2):192-7.

14. Ukayama H. General Laboratory Manual. Department of Pathology, Hackensack University Medical Centre; 2010. P. 117.

15. Hsueh WA, Quinones MJ. Role of endothelial dysfunction in insulin resistance. Am J Cardiol 2003; 92(4A):10J-7.

16. Manjunatha Goud BK, Nayal B, Sarsina DO, Sathisha TG, Shivashanker S, Devaki, RN. Relation of calculated $\mathrm{HbA} 1 \mathrm{c}$ with fasting plasma glucose and duration of diabetes. Int J Appl Biol Pharm Technol 2011; 2(2):58-61.

17. American diabetes association, American diabetes association's new clinical practice recommendations promote $\mathrm{HbA} 1 \mathrm{C}$ as diagnostic test for diabetes, standards of medical care in diabetes. Diabetes Care 2010; 33:S11-69.

18. Duk-Hee Lee, Gross MD, Steefers MW, Jacobs DR. Is serum gamma-glutamyl 
transferase a biomarker of xenobiotics, which are conjugated by glutathione? Arterioscler Thromb Vasc Biol 2008; 28:e26-8.

19. Ruttmann E, Brant LJ, Concin H, Diem G, Rapp K. The Vorarlberg health monitoring and promotion program study group. Gamma glutamyltransferase as a risk factor for cardiovascular disease mortality: an epidemiological investigation in a cohort of 163944 Austrian adults. Circulation 2005; 112(14):2130-7.

21. Nakanishi N, Suzuki, Tatara K. Serum gamma glutamyltransferase and risk of metabolic syndrome and type 2 diabetes in middle-aged Japanese men. Diabetes Care 2004; 27:142732.

22. Gholamreza Y, Mostafa S, Mahboobeh Y, Hamid $\mathrm{N}$. Role of gamma-glutamyl transferase in diagnosis of impaired glucose tolerance and metabolic syndrome: A prospective cohort research from the Kerman Coronary Artery Disease Risk Study (KERCADRS). Diabetes \& Metabolic Syndrome: Clin Res Rev 2012; 6:190 -4 .

23. Andre $\mathrm{P}$, Balkau B, Born C, Charles MA, Eschwege ED. E.S.I.R. study group. Three-year increase of gamma-glutamyl transferase level and dependent of type 2 diabetes in middle-aged men and women: the D.E.S.I.R. cohort. Diabetologia 2006; 49:2599-603.

24. Lippi G, Targher G, Montagnana M, Salvango GL, Guidi GC. Relatioship between $\gamma$ - glutamyl transferase, lipids and lipoprotein (a) in the general population. Clin Chem Acta 2007; 384:163-6. 